"The objective of the paper is to present the importance of consumption vis-à-vis population and development and to discuss their direct linkages. It draws on the Vallentyne 'demotechnic' index to combine and interrelate population and consumption, obtaining estimates which allow fair comparisons of countries in terms of their global environmental stress.

The conclusions obtained from these estimates of population adjusted by consumption seriously question the assumption that countries with larger populations pose a greater environmental risk. They show, for example, that the US and former USSR each with relatively low populations, have 'consumption adjusted populations' that dramatically surpass those of the more populated but less developed countries of China and India. Sustainable development ... is premised on a balance between population and consumption within the overall limits imposed by nature. It has become clear ... that not only population but also consumption have to be reduced if sustainability is to be achieved. What is needed ... is rolling back consumption levels in the North and reducing population growth in the South."

\title{
Consumption: the other side of population for development ${ }^{*}$
}

\author{
Francisco J. Mata ${ }^{1}$, Lawrence J. Onisto ${ }^{2, * *}$, John R. Vallentyne ${ }^{3, \mp}$ \\ ${ }^{1}$ Earth Council, Apartado 2323-1002, San José, Costa Rica \\ ${ }^{2}$ Environment and Sustainable Development Division, Ontario Hydro, 700 University Avenue, Toronto, \\ Ontario M5G 1X6, Canada \\ ${ }^{3}$ Canada Centre for Inland Waters, PO Box 5050, Burlington, Ontario L7R 4A6, Canada
}

\begin{abstract}
World population is growing at an alarming rate, and thus population has become a major topic in sustainable development fora. In these debates, it is often asserted that developing countries with large populations pose a greater world environmental threat than developed countries with smaller populations. Because of this view, developed countries often appeal to developing countries to reduce their population growth. However, it is well known that developed countries have higher levels of consumption than developing countries and that consumption also exerts pressure on the environment. Although awareness of the importance of consumption for development and the recognition of the relationship between population and consumption are increasing, population still takes precedence over consumption as a major concern for sustainability. Our objective here is to present the importance of consumption vis-à-vis population for development and to discuss their direct linkages. We draw on the work by Vallentyne (1978: Verh Int Verein Limnol 20:1-12; and 1982: Biol Int 5:10-12), and use his 'demotechnic' index to combine and inter-relate population and consumption. By doing so, we are able to adjust population by consumption, obtaining estimates that allow fair comparisons of countries in terms of their global environmental stress. The conclusions obtained from the estimates of population adjusted by consumption seriously question the assumption that countries with larger populations pose a greater environmental risk. Sustainable development is premised on a balance between population and consumption within the overall limits imposed by nature. Therefore, it becomes clear that not only population but also consumption have to be reduced if sustainability is to be achieved.
\end{abstract}

KEY WORDS: Population $\cdot$ Consumption $\cdot$ Development $\cdot$ Sustainability $\cdot$ Demotechnic $\cdot$ D-index

* Originally prepared for and presented at the International Conference on Population and Development (ICPD) Cairo, Egypt, 5-13 September 1994 [Previously circulated by the Earth Council San Jose, Costa Rica]

\footnotetext{
${ }^{* *}$ Corresponding author. Email: onisto@bell.net

${ }^{\ddagger}$ Deceased
}

(C) Inter-Research $2012 \cdot$ www.int-res.com 


\section{INTRODUCTION}

World population is growing at an alarming rate. According to projections by the United Nations, annual increments in the world population above 90 million persons are likely to occur until the year 2015.

This increase in the world population, added to the fact that we live on a finite planet with many nonrenewable resources, presents a pessimistic scenario for the future generations. Therefore, population has become a major topic of discussion in sustainable development fora. Although population is one important factor to achieve sustainability, consumption is another important factor that often tends to be disregarded altogether. However, the birth of a child in a developed country imposes more stress on the global environment than the birth of a child in a developing country because of differences in consumption patterns. Furthermore, population and consumption are interrelated.

The Rio Declaration 1992 (www.un.org/documents/ ga/conf151/aconf15126-1annex1.htm) and Agenda 21 1992 (www.un.org/esa/dsd/agenda21/index.shtml) recognize the importance of population and consumption for sustainable development. Agenda 21 in particular proposes (1) to incorporate demographic trends and factors in the global analysis of environment and development issues; (2) to promote patterns of consumption and production that reduce environmental stress and at the same time meet the basic needs of humanity; and (3) to develop a better understanding of the role of consumption and how to bring about more sustainable consumption patterns. However, while the importance and implications of a growing population are well understood, the 'growing recognition of the importance of addressing consumption has not yet been matched by an understanding of its implications' (Agenda 21, Ch. 4, Sec. 4.6). Furthermore, in spite of the fact that the Rio Declaration and Agenda 21 acknowledge the relationship between population and consumption, no concrete proposals have yet been made on how to integrate these 2 development variables.

Population and consumption are also reflected in the International Conference on Population and Development (ICPD) Programme of Action (www.un. org/ecosocdev/geninfo/population/icpd.htm). However, there is an explicit predominance of population in its programme as expressed in the objective 'to fully integrate population concerns into development strategies, planning, decision-making and resource allocation at all levels and in all regions, with the goal of meeting the needs, and improving the quality of life, of present and future generations' (ICPD Programme of Action, Ch. 3, Sec. A).
If population dominates the development discussion, then it is natural to consider population as a valid sustainable development indicator. In this view, sustainability can be operationalized by limiting population below the carrying capacity of the Earth. The international action called for, then, is to induce countries to limit their populations (see ICPD Programme of Action, Ch. 6).

Sustainable development is based on the premise that population and per capita consumption operate within the ability of the ecosystem to carry the demand on resources and assimilate the wastes, indefinitely. Population effects vary widely due to vast regional differences in effects and sensitivities. While large populations exert considerable stress on their ecosystems, small populations with high rates of consumption can eclipse the effect of larger populations operating at lower rates of consumption. Sustainable development requires that both population and consumption be taken into account. Per capita consumption of energy may exceed many times the physiological energy requirements of humans (Vallentyne 1982). Other authors have also suggested that the consumption multiplier is an important part of the 'net effect' on environment and sustainability (Goodland et. al. 1994). The consumption factor and its ability to amplify even small populations are examined further in the present study.

\section{INTEGRATING POPULATION AND CONSUMPTION}

Humans not only exert pressure on the environment because of basic physiological needs for survival, but also due to their activities aimed at converting raw materials into products and services. Therefore, a measure of the stress of humans on the environment must reflect the needs of the physiological system as well as those of the technological system used for production and consumption.

In this regard, technology can be considered as an extension of human metabolism, and the requirements for this technology can be related to physiological needs. This argument provides the basis for calculating a 'consumption-adjusted population', which is obtained by adding to the existing population an equivalent number of individuals with energy demands for their physiological needs equivalent to the country's energy requirements for its technological system. This conversion is analogous to the use of 'horsepower' in inter-relating the power of horses and machines. The adjustment to the population is 
made by means of the demotechnic, or D-index (Vallentyne 1982), which is equal to the ratio of technological energy consumption to physiological energy consumption, expressed in the same units (see Appendix 1 for details on calculation).

Estimating the consumption of resources is extremely difficult, and thus energy consumption, although imperfect, is the best available surrogate for consumption (Goodland et al. 1994). Therefore, we use the D-index to interrelate population and consumption.

\section{POPULATION ADJUSTED BY CONSUMPTION}

Table 1 presents the D-indexes, populations and consumption-adjusted populations for countries ordered in descending magnitude by D-index for
1990 (see the supplement at www.int-res.com/ articles/suppl/e012p015_supp.pdf for this information ordered alphabetically by country). The Dindexes vary from 198.49 in Qatar to 0.39 in Comoros. Countries towards the top of the list use a higher proportion of energy for their technological system (production/consumption) as compared to the physiological needs of their inhabitants, revealing larger consumption patterns. This list is headed by countries in which energy is relatively cheap and financial resources are available. Developing countries, on the other hand, are at the bottom of this list.

Fig. 1 shows the national populations and consumption-adjusted populations in 1990. Clear differences between these 2 maps can be observed. The USA and the (former) USSR, each with relatively low

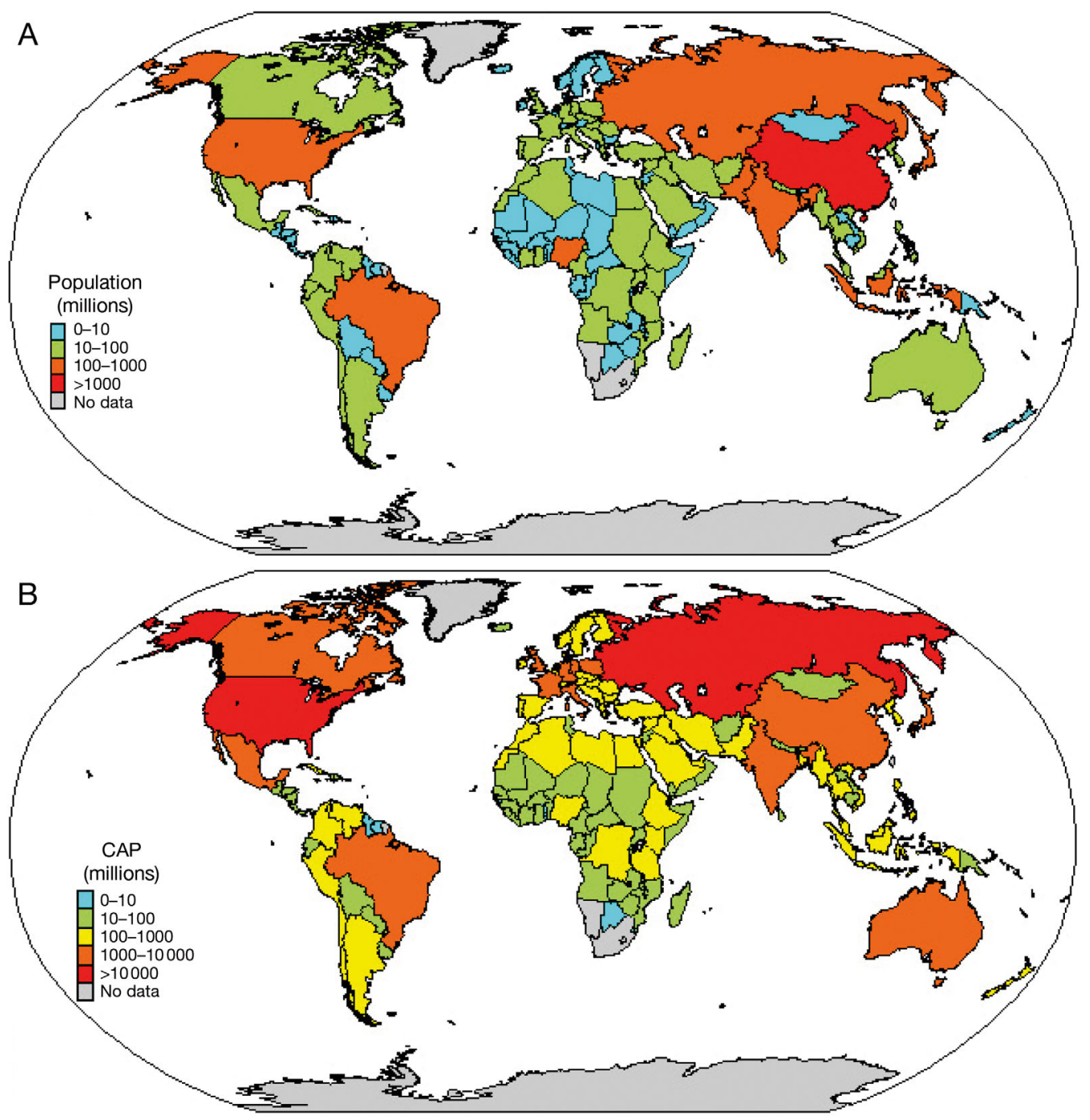

Fig. 1. Map of the world showing (A) population and (B) consumption adjusted population (CAP) by country 
Table 1. Demotechnic (D-) indexes, population (in thousands), and consumption-adjusted population (CAP, in thousands) by country for 1990 ordered by D-index. Data are taken from the Human Development Report 1993 (http://hdr.undp.org/en/reports/global/ hdr1993/) and the World Resources Data Base 1992-93 (now known as the World Resouces Institute [WRI] Earthtrends Data Base; http:// earthtrends.wri.org/searchable_db/index.php?theme=6\&variable_ID=351\&action=select_countries). The D-indexes for 1990 use population data for 1990 and energy data for 1989 due to the availability of published data at the time of preparation of the present study

\begin{tabular}{|c|c|c|c|c|c|c|c|c|c|}
\hline Rank & Country & D-index & Population & CAP & Rank & Country & D-index & Population & CAP \\
\hline 1 & Qatar & 198.49 & 368 & 73412 & 56 & Albania & 13.74 & 3245 & 47831 \\
\hline 2 & United Arab Emirates & 163.38 & 1589 & 261200 & 57 & Malaysia & 13.40 & 17891 & 257630 \\
\hline 3 & Bahrain & 128.50 & 516 & 66822 & 58 & Iran, Islamic Rep. & 13.04 & 54607 & 766682 \\
\hline 4 & Canada & 118.11 & 26521 & 3158916 & 59 & Chile & 12.92 & 13173 & 183368 \\
\hline 5 & Norway & 109.24 & 4212 & 464331 & 60 & Lebanon & 12.73 & 2701 & 37085 \\
\hline 6 & USA & 91.26 & 249224 & 22993406 & 61 & Reunion & 10.90 & 598 & 7116 \\
\hline 7 & Iceland & 83.23 & 253 & 21310 & 62 & Uruguay & 10.80 & 3094 & 36509 \\
\hline 8 & Sweden & 78.55 & 8444 & 671720 & 63 & Colombia & 10.38 & 32978 & 375290 \\
\hline 9 & Kuwait & 68.17 & 2039 & 141038 & 64 & Costa Rica & 9.68 & 3015 & 32200 \\
\hline 10 & Finland & 65.73 & 4975 & 331982 & 65 & Fiji & 9.36 & 764 & 7915 \\
\hline 11 & Germany, Dem. Rep. ${ }^{a}$ & 64.50 & 16249 & 1064310 & 66 & Swaziland & 9.30 & 788 & 8116 \\
\hline 12 & Australia & 63.42 & 16873 & 1086959 & 67 & Turkey & 9.04 & 55868 & 560915 \\
\hline 13 & $\mathrm{USSR}^{\mathrm{a}}$ & 57.31 & 288595 & 16827974 & 68 & Panama & 9.01 & 2418 & 24204 \\
\hline 14 & Belgium & 55.84 & 9845 & 559590 & 69 & Zimbabwe & 8.77 & 9709 & 94857 \\
\hline 15 & Netherlands & 55.74 & 14951 & 848320 & 70 & Iraq & 8.77 & 18920 & 184848 \\
\hline 16 & New Zealand & 55.46 & 3392 & 191512 & 71 & Syrian Arab Rep. & 8.66 & 12530 & 121040 \\
\hline 17 & Czechoslovakia $^{\mathrm{a}}$ & 53.29 & 15667 & 850561 & 72 & Yemen, $\mathrm{PDR}^{\mathrm{a}}$ & 8.52 & 2491 & 23714 \\
\hline 18 & Saudi Arabia & 52.26 & 14134 & 752777 & 73 & Ecuador & 8.36 & 10587 & 99094 \\
\hline 19 & Germany, Fed. Rep. $^{a}$ & 49.75 & 61324 & 3112193 & 74 & Thailand & 8.33 & 55702 & 519700 \\
\hline 20 & Trinidad \& Tobago & 47.03 & 1281 & 61526 & 75 & Jordan & 8.29 & 4009 & 37244 \\
\hline 21 & Switzerland & 45.93 & 6609 & 310160 & 76 & Algeria & 7.91 & 24960 & 222394 \\
\hline 22 & UK & 44.36 & 57237 & 2596270 & 77 & Mauritius & 7.88 & 1082 & 9608 \\
\hline 23 & France & 44.13 & 56138 & 2533508 & 78 & Jamaica & 7.70 & 2456 & 21367 \\
\hline 24 & Bulgaria & 42.97 & 9010 & 396170 & 79 & China & 7.19 & 1139060 & 9328901 \\
\hline 25 & Austria & 42.59 & 7583 & 330543 & 80 & Zambia & 6.92 & 8452 & 66940 \\
\hline 26 & Singapore & 40.89 & 2723 & 114066 & 81 & Tunisia & 6.90 & 8180 & 64622 \\
\hline 27 & Denmark & 40.73 & 5143 & 214617 & 82 & Liberia & 6.79 & 2575 & 20059 \\
\hline 28 & Romania & 39.02 & 23272 & 931345 & 83 & Papua New Guinea & 6.71 & 3874 & 29869 \\
\hline 29 & Japan & 37.75 & 123460 & 4784075 & 84 & Egypt, Arab Rep. & 6.62 & 52426 & 399486 \\
\hline 30 & Poland & 37.65 & 38423 & 1485049 & 85 & Peru & 6.42 & 21550 & 159901 \\
\hline 31 & Hungary & 35.62 & 10552 & 386414 & 86 & Paraguay & 6.26 & 4277 & 31051 \\
\hline 32 & Italy & 34.06 & 57061 & 2000559 & 87 & Botswana & 6.04 & 1304 & 9180 \\
\hline 33 & Libya & 33.29 & 4545 & 155848 & 88 & Mauritania & 5.92 & 2024 & 14006 \\
\hline 34 & Ireland & 30.37 & 3720 & 116696 & 89 & Bhutan & 5.72 & 1516 & 10188 \\
\hline 35 & Oman & 28.19 & 1502 & 43843 & 90 & Congo & 5.66 & 2271 & 15125 \\
\hline 36 & Venezuela & 27.09 & 19735 & 554356 & 91 & Nicaragua & 5.30 & 3871 & 24387 \\
\hline 37 & Greece & 26.78 & 10047 & 279106 & 92 & Kenya & 5.25 & 24031 & 150194 \\
\hline 38 & Korea, DPR & 26.52 & 21773 & 599193 & 93 & Honduras & 4.99 & 5138 & 30777 \\
\hline 39 & Israel & 24.72 & 4600 & 118312 & 94 & Cameroon & 4.98 & 11833 & 70761 \\
\hline 40 & Spain & 24.36 & 39187 & 993782 & 95 & Guatemala & 4.88 & 9197 & 54078 \\
\hline 41 & Yugoslavia $^{a}$ & 24.06 & 23807 & 596603 & 96 & Malawi & 4.83 & 8754 & 51036 \\
\hline 42 & Korea, Rep. & 20.91 & 42793 & 937595 & 97 & Guyana & 4.81 & 796 & 4625 \\
\hline 43 & Cyprus & 20.91 & 701 & 15359 & 98 & El Salvador & 4.74 & 5252 & 30146 \\
\hline 44 & Argentina & 18.16 & 32322 & 619290 & 99 & Dominican Rep. & 4.59 & 7170 & 40080 \\
\hline 45 & Gabon & 17.56 & 1172 & 21752 & 100 & Ghana & 4.54 & 15028 & 83255 \\
\hline 46 & Cuba & 17.34 & 10608 & 194551 & 101 & Philippines & 4.52 & 62413 & 344520 \\
\hline 47 & Mongolia & 17.26 & 2190 & 39989 & 102 & Indonesia & 4.42 & 184283 & 998814 \\
\hline 48 & Malta & 16.80 & 353 & 6283 & 103 & Nigeria & 4.24 & 108542 & 568760 \\
\hline 49 & Guadeloupe & 16.54 & 343 & 6016 & 104 & Bolivia & 4.14 & 7314 & 37594 \\
\hline 50 & Portugal & 16.34 & 10285 & 178342 & 105 & Cote d'Ivoire & 4.09 & 11997 & 61065 \\
\hline 51 & Hong Kong & 15.91 & 5851 & 98940 & 106 & Gambia & 3.81 & 861 & 4141 \\
\hline 52 & Mexico & 15.25 & 88598 & 1439718 & 107 & Central African Rep. & 3.62 & 3039 & 14040 \\
\hline 53 & Suriname & 15.09 & 422 & 6790 & 108 & Tanzania & 3.60 & 27318 & 125663 \\
\hline 54 & Barbados & 15.09 & 255 & 4103 & 109 & India & 3.58 & 853094 & 3907171 \\
\hline 55 & Brazil & 14.00 & 150368 & 2255520 & 110 & Zaire $^{a}$ & 3.43 & 35568 & 157566 \\
\hline
\end{tabular}


Table 1 (continued)

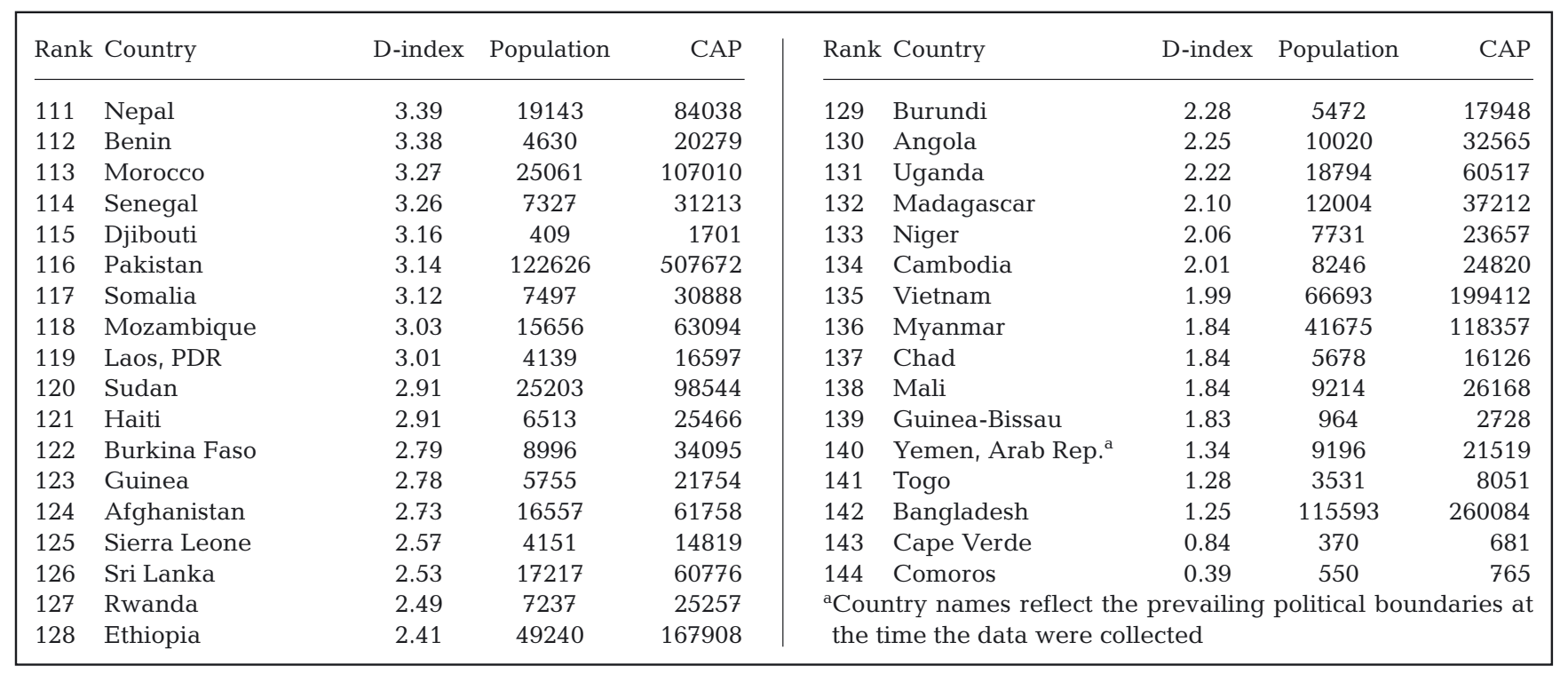

populations, have consumption-adjusted populations that dramatically surpass those of China and India. Similarly, Canada, with less than $4 \%$ of the population of India, has almost the same consumption-

Table 2. Population and consumption-adjusted population (CAP), in millions for selected countries in 1990

\begin{tabular}{|lrr|}
\hline Country & Population & CAP \\
\hline China & 1139 & 9329 \\
India & 853 & 3907 \\
USSR & 289 & 16828 \\
USA & 249 & 22993 \\
Canada & 27 & 3159 \\
\hline
\end{tabular}

adjusted population as India. Table 2 presents the data for these 5 countries.

Table 3 lists countries that have the greatest opportunities and responsibilities to lower the consumptionadjusted population of the Earth.

\section{CONCLUSIONS}

Population by itself is not a good indicator of global environmental stress. Countries with small populations can have greater environmental stress than countries with large populations. Population can be used to measure one facet of environmental stress,

Table 3. Highest contributing countries according to consumption-adjusted population (CAP; in thousands) in 1990

\begin{tabular}{|c|c|c|c|c|c|c|c|}
\hline Rank & Country & CAP & Contribution (\%) & Rank & Country & CAP & Contribution (\%) \\
\hline 1 & USA & 22993406 & 22.08 & 16 & Indonesia & 998814 & 0.96 \\
\hline 2 & USSR & 16827974 & 16.16 & 17 & Spain & 993782 & 0.95 \\
\hline 3 & China & 9328901 & 8.96 & 18 & Korea, Rep. & 937595 & 0.9 \\
\hline 4 & Japan & 4784075 & 4.59 & 19 & Romania & 931345 & 0.89 \\
\hline 5 & India & 3907171 & 3.75 & 20 & Czechoslovakia & 850561 & 0.82 \\
\hline 6 & Canada & 3158916 & 3.03 & 21 & Netherlands & 848320 & 0.81 \\
\hline 7 & Germany, Fed. Rep. & 3112193 & 2.99 & 22 & Iran, Islamic Rep. & 766682 & 0.74 \\
\hline 8 & UK & 2596270 & 2.49 & 23 & Saudi Arabia & 752777 & 0.72 \\
\hline 9 & France & 2533508 & 2.43 & 24 & Sweden & 671720 & 0.64 \\
\hline 10 & Brazil & 2255520 & 2.17 & 25 & Argentina & 619290 & 0.59 \\
\hline 11 & Italy & 2000559 & 1.92 & 26 & Korea, DPR & 599193 & 0.58 \\
\hline 12 & Poland & 1485049 & 1.43 & 27 & Yugoslavia & 596603 & 0.57 \\
\hline 13 & Mexico & 1439718 & 1.38 & 28 & Nigeria & 568760 & 0.55 \\
\hline 14 & Australia & 1086959 & 1.04 & 29 & Turkey & 560915 & 0.54 \\
\hline 15 & Germany, Dem. Rep. & 1064310 & 1.02 & & Total & 89270886 & 86 \\
\hline
\end{tabular}


namely the use of resources to satisfy basic human needs. However, populations can vary in their demands for resources needed for production/consumption. A better indicator of global environmental stress is obtained by adjusting population by consumption.

The reduction of population has been the driving force in international events and negotiations regarding sustainable development. But population and consumption are 2 sides of the same coin. Sustainability is a function of scale. On a national level, population tends to be more important than consumption-adjusted population, whereas the reverse is true on a global level. Therefore, a reduction of population growth in developing countries and a reduction of consumption in developed countries are both needed to achieve sustainability.

Acknowledgements. The authors gratefully acknowledge the technical and logistic assistance provided by Maurice Strong, Alicia Barcena, and the staffs of the Earth Council and Environment and Sustainable Development Division of Ontario Hydro.

\section{LITERATURE CITED}

Goodland R, Daly H, Kellenberg J (1994) Burden sharing in the transition to environmental sustainability. Futures 26: 146-155

Vallentyne JR (1978) Presidential address: today is yesterday's tomorrow. Verh Int Verein Limnol 20:1-12

Vallentyne JR (1982) A new approach to membership dues schedules for use by international organizations. Biol Int 5: $10-12$

Appendix 1. Calculation of the demotechnic (D) index

\section{Demotechnic calculations and conversions}

The word 'demotechnic' (demos meaning population; techne meaning technology) expresses the combined energy expended through the activities of humans and their technology, in common units. The comparisons can be made in terms of population and consumption-adjusted population. The comparison is similar to that between horses and machines in terms of horsepower.

To make this conversion, a common energy unit is needed. This unit is called a D unit (demotechnic unit). One D unit is defined as the physiological energy consumption of an average human over the course of a year ( $365.25 \mathrm{~d}$ ) calculated at a rate of $2333 \mathrm{kcal} \mathrm{d}^{-1}$. This value corresponds to the daily calorie requirement per capita 1988-90 for medium human development countries as reported in the Human Development Report 1993 (http:// hdr.undp.org/en/reports/global/hdr1993/) One D unit is

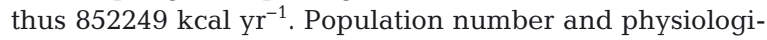
cal energy consumption in D units are numerically equal.

The D-index (demotechnic index) is defined as the ratio of technological energy consumption to physiological energy consumption with both expressed in common units. This provides a measure of the technological metabolism associated with an average person in a specific national or regional setting.

Another key concept is consumption-adjusted population. This is defined as the population of a country plus the population multiplied by the $\mathrm{D}$-index. The population component is a measure of physiological (food) energy consumption, and the consumption-adjusted population is a measure of total energy consumption (physiological plus technological energy consumption).

An example may help to make this clear. Table 21.2.6 in the World Resources Data Base 1992-93 (now known as the World Resources Institute [WIR] Earthtrends Data http://earthtrends.wri.org/searchable_db/index.php?theme $=6 \&$ variable_ID $=351 \&$ action=select_countries) lists the population of Canada in 1990 as 26520000 , and the total technological energy consumption in 1989 as 421.76 gigajoules per capita. Based on a conversion factor of $1 \mathrm{D}$ unit $=3.5709$ gigajoules, the D-index for Canada can be calculated to be $421.76 / 3.5709=118.11$. Similarly, the total energy consumption for Canada in 1989-90, or consumer-adjusted population in D units, was $26520000(118.1+1)=3158790$.

\section{Strength snd weakness of the demotechnic approach}

\section{Strengths}

(1) Data on consumption-adjusted populations provide a more realistic basis for viewing the effects of human activities on the biosphere than data on populations.

(2) Because demotechnic units are expressed in energy consumption per unit time, consumption-adjusted population and ecosystem energy production (e.g. photosynthesis, fish catches, plant harvests) are directly relatable. This could eventually permit the calculation of carrying capacities of ecosystems for human populations of different technological lifestyles.

\section{Weaknesses}

(1) The relationship between consumption-adjusted population and environmental impacts varies depending on the type of energy considered. Different types of energy also have different environmental impacts on different scales. Coal burning, for example, creates local pollution from particulates, regional pollution from sulphur oxides, global pollution from carbon dioxide, and the loss of a nonrenewable resource. Hydroelectric power, on the other hand, is primarily local or, at the most, regional, in its effects, and represents a renewable resource. While it is feasible to calculate environmental impacts on various scales, this has not been done in the present study.

(2) Demotechnic data do not reflect specific classes of waste (e.g. solid waste, toxics, radioactives) that have different impacts on environment. 